\title{
MULTI-PARAMETER GENERALIZATION OF RADO-POPOVICIU INEQUALITIES
}

\author{
JING ZHANG AND HUAN-NAN SHI
}

Abstract. By using methods on the theory of majorization, new generalizations of Rado's inequality and Popoviciu's inequality which involves multi-parameter are established.

Mathematics subject classification (2010): Primary 26D15, 26E60, 26 B25.

Keywords and phrases: Rado's inequality, Popoviciu's inequality, majorization, Schur-concavity, symmetric function, dual form, convex function.

\section{REFERENCES}

[1] D. S. Mitrinović, P. M. Vasić, Analytic Inequalities, Springer-Verlag, Berlin, Heidelberg, 1970, 74-94.

[2] D. S. Mitrinović, J. E. PeČArić, A. M. Fink, Classical and New Inequalities in Analysis, Kluwer Academic Publishers, Dordrecht, 1993, 21-56.

[3] Chung-Lie Wang, Inequalities of the Rado-Popoviciu type for functions and their applications, J. Math. Anal. Appl., 100 (2) (1984), 436-446.

[4] Huan-Nan Shi, A new generalization of the Popoviciu's inequality, J. Sichuan Norm. Univ. Nat. Sci. Ed., 25 (5) (2002), 510-511, (in Chinese).

[5] VAsile MiheşAn, Rado and Popoviciu type inequalities for pseudo arithmetic and geometric means, Int. J. Pure Appl. Math., 23 (3) (2005), 293-297.

[6] M. Bencze, A generalization of T. Popoviciu's inequality, Gazeta Mat., 96 (1991), 159-161.

[7] H. AlzER, Rado-type inequalities for geometric and harmonic means, J. Pure Appl. Math. Sci., 24 (1989), 125-130.

[8] S. Wu, L. Debnath, Weighted generalization of Rado's inequality and Popoviciu's inequality, Appl. Math. Lett., 21 (2008), 313-319.

[9] A. W. Marshall, I. Olkin, And B. C. ARnold, Inequalities: Theory of Majorization and Its Application (Second Edition), Springer, New York, 2011.

[10] B. Y. WANG, Foundations of Majorization Inequalities, Beijing Normal University Press, Beijing, 1990, (in Chinese).

[11] H.-N. SHI, Theory of Majorization and Analytic Inequalities, Harbin Institute of Technology Press, Harbin, 2012, (in Chinese). 